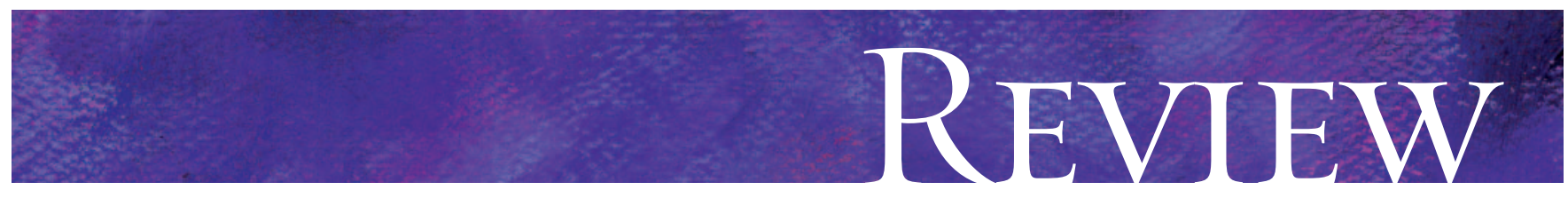

\title{
Hypertriglyceridemia: its etiology, effects and treatment
}

\author{
George Yuan, Khalid Z. Al-Shali, Robert A. Hegele
}

\section{ABSTRACT}

Elevated plasma triglyceride concentration is a common biochemical finding, but the evidence for the benefit of treating this lipid disturbance remains less robust than that for treating elevated low-density lipoprotein-cholesterol. Part of the difficulty in the provision of specific recommendations has been the frequent coexistence of elevated triglycerides with other conditions that affect cardiovascular disease risk, such as depressed high-density lipoprotein-cholesterol, obesity, metabolic syndrome, proinflammatory and prothrombotic biomarkers, and type 2 diabetes. Recent investigations of outcomes of cardiovascular disease when medications are used to reduce triglyceride levels suggest that, although a net benefit probably exists, both relative and absolute risk reductions seem underwhelming when compared with the benefit of reducing low-density lipoprotein-cholesterol levels with treatment. However, the totality of evidence suggests that elevated triglyceride levels likely contribute independently to increased risk of cardiovascular disease, although there is no consensus about appropriate target levels. Furthermore, severe hypertriglyceridemia is associated with an increased risk of acute pancreatitis, irrespective of its effect on risk of cardiovascular disease. We review the causes and classification of elevated triglyceride levels, the clinical manifestations of primary hypertriglyceridemia and the management of patients with elevated triglyceride levels.

CMAJ 2007:176(8):1113-20

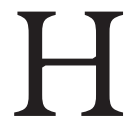
ypertriglyceridemia refers to a fasting plasma triglyceride measurement that is increased, typically above the 95th percentile for age and sex - although additional quantitative or qualitative lipoprotein abnormalities can also be present. ${ }^{1,2}$ Patients can fluctuate between hypertriglyceridemic states: given an appropriate metabolic stress, mild or moderate hypertriglyceridemia can deteriorate into severe hypertriglyceridemia. Elevated plasma triglyceride concentrations contribute to increased risk of car$m$ diovascular disease, both directly and because such elevations "keep bad company" with associated risk factors such as obesity, metabolic syndrome, proinflammatory and prothrombotic biomarkers, and type 2 diabetes mellitus. ${ }^{2}$ The increased risk of acute pancreatitis is an additional consideration when a patient's triglyceride level is very high (typically $>$ Io $\mathrm{mmol} / \mathrm{L}$ ).
The two main sources of plasma triglycerides (also known as triacylglycerol) are exogenous (i.e., from dietary fat) and carried in chylomicrons, and endogenous (from the liver) and carried in very-low-density lipoprotein (VLDL) particles. In capillaries within fat and muscle tissue, these lipoproteins and chylomicrons are hydrolyzed by lipoprotein lipase into free fatty acids. After a meal, over $90 \%$ of the circulating triglycerides originate in the intestine and are secreted in chylomicrons, whereas during periods of fasting, endogenous triglycerides secreted by the liver as VLDL predominate. The increase in plasma of triglyceride-rich lipoproteins results from increased production from the liver and intestine (by means of upregulated synthetic and secretory pathways) or through decreased peripheral catabolism (mainly from reduced lipoprotein lipase activity).

\section{Classification}

Hypertriglyceridemia can be divided into primary and secondary types. In this postgenome era, a classification system for triglyceride disorders should be based upon molecular diagnoses, but a molecular basis for primary hypertriglyceridemia has been found in less than $5 \%$ of cases - and for secondary cases, no genetic susceptibility component that is reproducible. ${ }^{1}$ Most patients with hypertriglyceridemia have at least one secondary factor; nevertheless, not everyone with equivalent exposure to secondary factors develops equally severe dyslipidemia, which suggests a role for endogenous primary monogenic or polygenic susceptibility.

The Adult Treatment Panel III $^{3}$ of the National Cholesterol Education Program has suggested 4 triglyceride strata in the context of assessment of risk of cardiovascular disease: normal (< $\mathrm{I} .7 \mathrm{mmol} / \mathrm{L})$, borderline high $(\mathrm{I} .7-2.3 \mathrm{mmol} / \mathrm{L})$, high $(2.3-5.6 \mathrm{mmol} / \mathrm{L})$ and very high $(>5.6 \mathrm{mmol} / \mathrm{L})$. An alternative scheme, the World Health Organization-supported Fredrickson system of hyperlipoproteinemia phenotypes, was at one time widely taught, but has fallen into disuse. Here we review hypertriglyceridemia using clinical descriptive names, with corresponding Fredrickson numerical types included (in parentheses) for crossreference with older literature.

\section{Primary hypertriglyceridemia}

Chylomicrons normally are cleared rapidly from plasma by lipoprotein lipase with apolipoprotein (apo) C-II as a cofactor. Familial chylomicronemia (hyperlipoproteinemia type I, in 
the Fredrickson system) and primary mixed hyperlipidemia (type 5) are each characterized by the pathologic presence of chylomicrons after a I2-I4-hour period of fasting. Clinical features observed in both familial chylomicronemia and primary mixed hyperlipidemia include eruptive xanthomata (Fig. IA), lipemia retinalis (Fig. IC), hepatosplenomegaly, focal neurologic symptoms such as irritability, and recurrent epigastric pain with increased risk of pancreatitis. Samples of lipemic plasma develop a creamy supernatant when refrigerated overnight (Fig. IB); when the plasma is tested, fasting triglyceride measurements are typically above $\mathrm{Io} \mathrm{mmol} / \mathrm{L}$ in cases of either familial chylomicronemia or primary mixed hyperlipidemia.

Key distinguishing features of familial chylomicronemia and primary mixed hyperlipidemia include initial manifestation during childhood for the former and in adulthood for

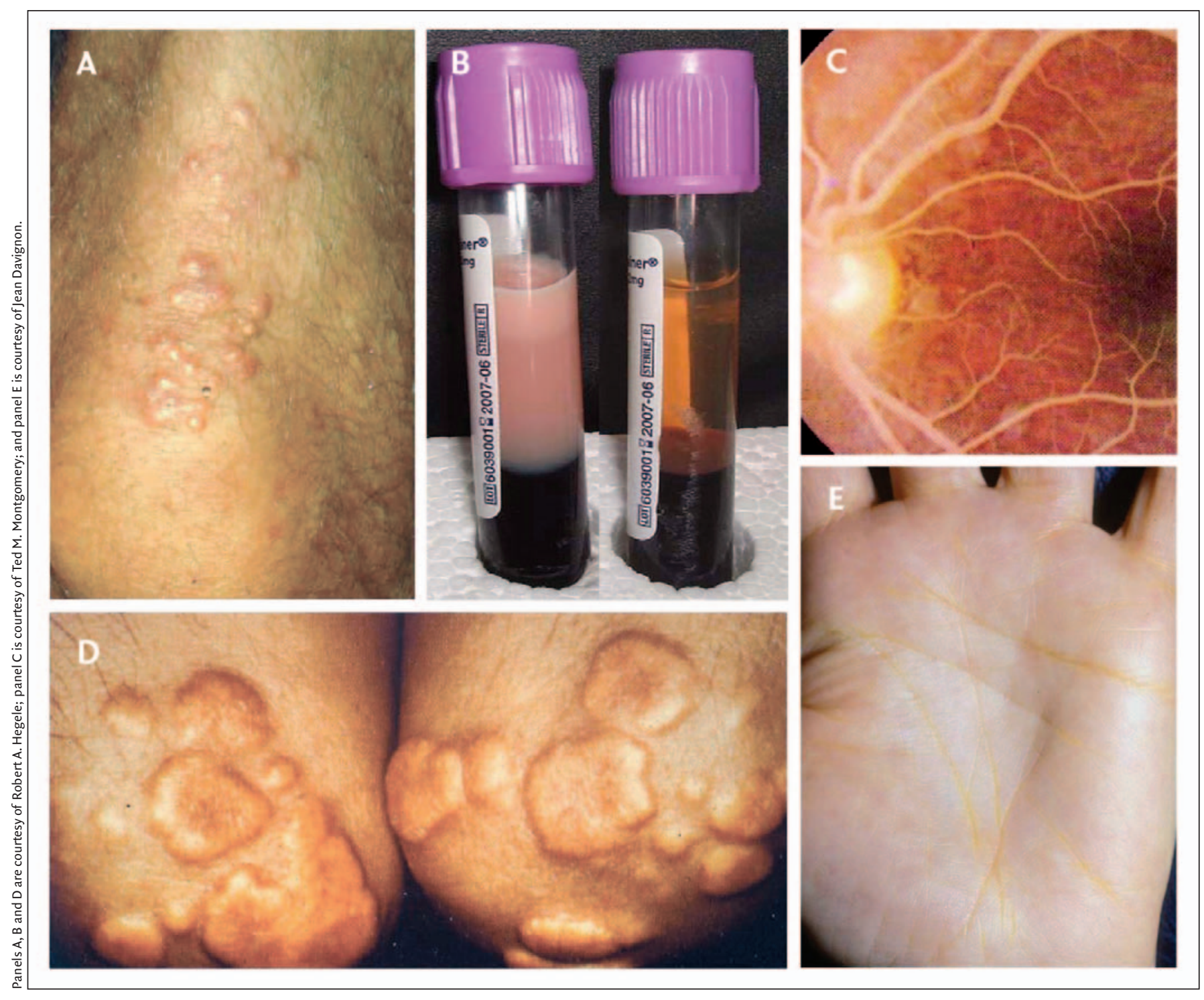

Fig. 1: Clinical manifestations of primary hypertriglyceridemia. A: Eruptive cutaneous xanthomas (here on a patient's knee) are filled with foam cells that appear as yellow morbiliform eruptions $2-5 \mathrm{~mm}$ in diameter, often with erythematous areolae. Most often associated with markedly elevated plasma chylomicrons in cases of familial chylomicronemia (hyperlipoproteinemia type 1) or primary mixed dyslipidemia (hyperlipoproteinemia type 5), they usually occur in clusters on the skin of the trunk, buttocks or extremities. B: Lipemic plasma. Whole blood has been allowed to stand at $4^{\circ} \mathrm{C}$ overnight. The sample on the left comes from a patient whose fasting total cholesterol result was $14.2 \mathrm{mmol} / \mathrm{L}$ and triglyceride concentration was $41.8 \mathrm{mmol} / \mathrm{L}$. The sample on the right comes from a normolipidemic subject. C: Lipemia retinalis. A milky appearance of the retinal vessels and pink retina can be seen when plasma triglyceride concentration exceeds $35 \mathrm{mmol} / \mathrm{L}$. D: Tuberous xanthomas, filled with foam cells, appear as reddish or orange, often shiny nodules, up to $3 \mathrm{~cm}$ in diameter. They are usually moveable and nontender. In patients with familial dysbetalipoproteinemia (hyperlipoproteinemia type 3 ), they usually appear on extensor surfaces; these are on a patient's elbows. E: Palmar crease xanthomas are filled with foam cells and appear as yellowish deposits within palmar creases. These skin lesions are pathognomonic for familial dysbetalipoproteinemia (hyperlipoproteinemia type 3 ). 
the latter; biochemically proven deficiency of lipoprotein lipase, apo CII activity or homozygous gene mutations in the former, with less severe functional deficiency and infrequent detection of gene mutations in the latter; a much lower population prevalence of the former (about $\mathrm{I}: \mathrm{IO}^{6}$ ) than of the latter (about $\mathrm{I}: \mathrm{IO}^{3}$ ); frequent presence of secondary factors in the latter; and a greater elevation of total cholesterol in the latter, relative to that in familial chylomicronemia. In biochemical diagnosis, familial chylomicronemia features a loss of lipoprotein lipase activity in plasma collected after an intravenous dose of heparin; however, few laboratories still perform this test.

Familial hypertriglyceridemia (hyperlipoproteinemia type 4) is defined by an isolated elevation of VLDL, which is not as triglyceride-rich as chylomicrons are. This familial disorder has a population prevalence of some $5 \%-10 \%$. Its molecular basis is still largely unknown but is likely to be polygenic, requiring a secondary factor for expression. ${ }^{1}$ Typically, patients with this disorder have moderately elevated plasma measurements of triglycerides (3-10 mmol/L), often with low levels of high-density lipoprotein-cholesterol (HDL-C). Familial hypertriglyceridemia is associated with increased risk of cardiovascular disease, obesity, insulin resistance, diabetes, hypertension and hyperuricemia.

The inheritance pattern of familial combined hyperlipoproteinemia (type $2 \mathrm{~B}$ ) is one of an autosomal dominant with variable penetrance, with a population prevalence of $2 \%-5 \% .{ }^{4}$ The defining lipoprotein abnormalities are increased VLDL and low-density lipoprotein (LDL) with depressed HDL, associated with an abnormal lipoprotein profile in at least one first-degree relative. Affected people occasionally have obligate heterozygosity for $L P L$ or $A P O C_{3}$ gene mutations, but the molecular basis underlying familial combined hyperlipoproteinemia is unknown in most instances. ${ }^{1} \mathrm{~A}$ recently defined gene that may be causative for this disorder is USF1, which encodes an upstream stimulatory factor, ${ }^{5}$ although sev-

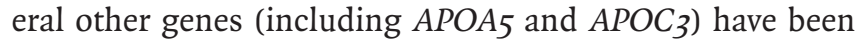
variably claimed as causative. ${ }^{6}$

Finally, familial dysbetalipoproteinemia (hyperlipoproteinemia type 3) has a population prevalence of $\mathrm{I}-2$ in $20000 . .^{7}$ The main observable lipoprotein abnormality is an increase in triglyceride-rich lipoprotein remnants, also known as intermediate-density lipoproteins or $\beta$-VLDL, which produce an equimolar elevation of plasma total cholesterol and triglyceride measurements. ${ }^{7}$ People with this disorder typically are homozygotic for the binding-defective $A P O E \mathrm{E}_{2}$ isoform, which differs from the common $\mathrm{E}_{3}$ isoform by a substitution of cysteine for the normal arginine at residue 158 in the receptor-binding domain. Phenotypic expression, however, usually requires accompanying factors such as obesity, type 2 diabetes or hypothyroidism. ${ }^{7}$ Plasma levels of LDL are decreased because of interrupted processing of VLDL. An increased VLDL-C:triglyceride ratio and E2/E2 homozygosity are diagnostic. Affected people often have tuberous or tuberoeruptive xanthomata on the extensor surfaces of their extremities (Fig. ID), planar- or palmarcrease xanthomata (Fig. IE) and increased risk of cardiovascular disease.

\section{Secondary hypertriglyceridemia}

Some metabolic conditions are frequently (but not universally) associated with high triglyceride results, suggesting that people who develop secondary hypertriglyceridemia might have a subtle inherited metabolic defect that confers susceptibility. Obesity is probably the metabolic stressor most frequently associated with hypertriglyceridemia, although associations with poorly controlled type 2 diabetes and excessive alcohol consumption are also common.

Obesity, metabolic syndrome, diabetes. People with excess visceral adipose tissue often have elevated triglyceride and low HDL-C levels. About $80 \%$ of men with a waist girth of $90 \mathrm{~cm}$ or more and a plasma triglyceride level of $2 \mathrm{mmol} / \mathrm{L}$ or more typically have a metabolic triad of nontraditional cardiovasculardisease markers: hyperinsulinemia and increased levels of apo B and small, dense LDL particles. This triad can increase the risk of cardiovascular disease by up to 20 times. ${ }^{8}$

Impairment of the ability of insulin to stimulate glucose uptake and inadequate compensation for insulin insensitivity underlie type 2 diabetes. Moreover, among insulin-resistant people without type 2 diabetes, hyperinsulinemia is associated with a cluster of metabolic abnormalities called the metabolic syndrome. ${ }^{9}$ This syndrome, seen in people with central obesity, strongly predicts a future onset of type 2 diabetes. It is characterized by glucose intolerance, dyslipidemia (specifically, triglycerides > $1.7 \mathrm{mmol} / \mathrm{L}$ and low HDL-C concentrations) and hypertension. ${ }^{3}$ Hypertriglyceridemia, both in the metabolic syndrome and in type 2 diabetes, results from increased plasma concentrations of VLDL, with or without chylomicronemia; ${ }^{9}$ deficient lipoprotein lipase activity; increased cholesteryl ester transfer protein activity; and increased flux of free fatty acids to the liver.

A fatty liver is often associated with hypertriglyceridemia in people with obesity and insulin resistance. Several definitions of the metabolic syndrome exist, ${ }^{9}$ and it has been debated whether the clustered risk factors impart any risk above the simple sum of the individual components. However, the concept of the metabolic syndrome has proven to be useful in emphasizing the importance of obesity, insulin resistance and related lipoprotein disturbances in the assessment of cardiovascular disease risk. Hypertriglyceridemia of obesity, the metabolic syndrome and type 2 diabetes improves with weight loss and glycemic control.

Alcohol. Hypertriglyceridemia associated with alcohol intake also mainly results from increased plasma VLDL, with or without chylomicronemia. In some alcohol users, plasma triglyceride measurements can remain within the normal range because of an adaptive increase in lipolytic activity. However, alcohol can also impair lipolysis, especially when a patient has a pre-existing functional deficiency of lipoprotein lipase, which leads to markedly increased plasma triglycerides.

Renal disease. Although elevated LDL-C is the dominant abnormality, nephrotic syndrome is also characterized by increases in apo B-containing lipoproteins, including VLDL. The complex relation between renal disease and lipoprotein metabolism is reviewed in depth elsewhere ${ }^{10}$ but the underlying mechanisms probably include overproduction by the 
liver, which concurrently increases albumin synthesis to compensate for renal protein wasting. Uremia is associated with elevated VLDL, which reflects impaired lipolysis, possibly from the toxic effect of uremic metabolites.

Pregnancy. During the third trimester of pregnancy, plasma triglyceride levels normally rise to as much as threefold, ${ }^{11}$ but this physiologic triglyceride increase has little clinical consequence. Marked triglyceride increases also result, however, when lipoprotein lipase activity is compromised. Although chylomicronemia during pregnancy is very rare, it can be complicated by pancreatitis, which can be fatal to both mother and fetus. ${ }^{12}$

Nonalcoholic fatty-liver disorder. This disorder may affect up to one-third of North Americans, which reflects the increasing prevalence of obesity, insulin resistance and metabolic syndrome. ${ }^{13,14}$ Among affected patients, up to one-third may also have nonalcoholic steatotic hepatitis. ${ }^{13,14}$ Lipotoxicity, oxidative stress, cytokines and proinflammatory mediators contribute to the progression from steatosis to nonalcoholic steatotic hepatitis. Elevated triglyceride and depressed HDL-C levels are the defining components of the dyslipidemia in nonalcoholic fatty-liver disorder. Small studies have indicated that treatment with statins is more effective than that with fibrates in correcting the dyslipidemia. ${ }^{15}$

Other medical conditions. Although hypothyroidism is usually associated with elevated LDL concentrations, trigly-

Box 1: Secondary causes of and contributors to hypertriglyceridemia

- Obesity

- Metabolic syndrome with triglyceride levels $>1.7 \mathrm{mmol} / \mathrm{L}$

- A diet with a positive energy-intake balance and a high fat or high glycemic index content

- Insufficient physical activity

- Alcohol consumption

- Diabetes mellitus, particularly type 2

- Renal disease, especially uremia or glomerulonephritis

- Hypothyroidism*

- Pregnancy: physiological triglyceride concentrations double during the third trimester

- An autoimmune disorder, such as a paraproteinemia or systemic lupus erythematosis

- Any of several types of medications, including

- Corticosteroids

- Estrogens, especially those taken orally

- Tamoxifen

- Antihypertensives: e.g., noncardioselective $\beta$-blockers, thiazides

- Isotretinoin

- Bile-acid-binding resins

- Cyclophosphamide

- Antiretroviral regimens, especially for HIV infections

- Psychotropic medications: phenothiazines, secondgeneration antipsychotics

*Less common a cause of hypertriglyceridemia than elevated total cholesterol levels. cerides may also be elevated. Paraproteinemias (e.g., hypergammaglobulinemia in macroglobulinemia, myeloma, lymphoma and lymphocytic leukemias) and autoimmune disorders (e.g., systemic lupus erythematosis) can also cause hypertriglyceridemia, probably through immune-mediated interference of lipolysis.

Medications. Many drugs increase triglyceride concentrations (Box I). If one is considered to cause hypertriglyceridemia, the indications for that medication should be reviewed. If dosage reductions, changes in route of administration or substitution with another class of medication are not practical, then marked elevations of triglycerides should be treated with diet or pharmacologic agents.

Patients taking highly active antiretroviral therapy, particularly protease inhibitors, frequently experience lipodystrophy, insulin resistance and dyslipidemia; up to $80 \%$ and $50 \%$ of patients develop hypertriglyceridemia and hypercholesterolemia, respectively. ${ }^{16}$ Combination highly active antiretroviral therapy was found to be associated with a $26 \%$ increase in relative risk of cardiovascular disease. ${ }^{17}$ Ritonavir and lopinavir are most strongly associated with dyslipidemias; ${ }^{16} 3$ reversetranscriptase inhibitors, the nucleoside stavudine and the nonnucleoside nevirapine ${ }^{16}$ and efavirenz,${ }^{18}$ less consistently so. Often, triglyceride levels can improve when agents are switched (if there is no compromise in antiretroviral efficacy)..$^{18,19}$ In one study, ${ }^{19}$ for instance, a change from a protease inhibitor to nevirapine or efavirenz reduced triglyceride levels by about $25 \%$; the addition of pravastatin or bezafibrate further reduced them by about $40 \%$.

Second-generation antipsychotic medications are known to be associated with obesity, hypertriglyceridemia, ${ }^{20}$ hyperglycemia and type 2 diabetes. ${ }^{21}$ Clozapine and olanzapine disturb metabolism the most; risperidone and quetiapine have intermediate effects; and aripiprazole and ziprasidone, the fewest. ${ }^{20}$ Psychiatric disorders, because of associated lifestyles, may also predispose those affected to metabolic disturbances. ${ }^{22}$ Patients taking second-generation antipsychotics should be monitored regularly (every 8-I2 months) for weight gain and changes in fasting plasma glucose and lipoprotein levels. ${ }^{21}$

\section{Triglycerides and atherosclerosis}

Moderate hypertriglyceridemia is almost certainly an independent risk factor for cardiovascular disease. The Prospective Cardiovascular Munster (PROCAM) study ${ }^{23}$ found increases in risk as triglyceride levels rose from $2.3 \mathrm{mmol} / \mathrm{L}$ to $9.0 \mathrm{mmol} / \mathrm{L}$ (after correction for other risk factors for cardiovascular disease). Other studies ${ }^{24}$ have shown a strong independent relation between plasma triglyceride levels and likelihood of cardiovascular disease. Meta-analyses of thousands of patients followed up for more than ro years showed that a triglyceride elevation of $1 \mathrm{mmol} / \mathrm{L}$ increased risk of cardiovascular disease by $32 \%$ in men and $76 \%$ in women, independent of HDL-C levels. ${ }^{25}$

Complex mechanisms that underlie the association of triglycerides and atherosclerosis obscure the detection of any direct causal relation. Proatherogenic metabolic or biochem- 
ical abnormalities (e.g., obesity, type 2 diabetes, decreased levels of HDL-C, increased small dense LDL, increased free fatty acids, dysglycemia, hyperinsulinemia, increased plasma viscosity, increased inflammatory molecules, impaired fibrinolysis, prothrombosis) are often associated with elevated levels of triglycerides. ${ }^{2,24,25}$ Furthermore, triglyceride-rich lipoproteins and their remnants may directly contribute to the formation of arterial-wall foam cells. Chylomicrons are not directly atherogenic, although there are rare reports of atherosclerosis in patients with hyperchylomicronemia. ${ }^{26}$ In contrast, chylomicron remnants, VLDL and intermediate-density liproproteins are atherogenic. ${ }^{27} \mathrm{~A}$ newer concept is that postprandial lipemia is an independent predictor of cardiovascular disease, ${ }^{28}$ although, since sample preparation and assay conditions are nonroutine, "postprandial" elevation of triglycerides has no operative definition.

\section{Hypertriglyceridemia and pancreatitis}

Hypertriglyceridemia increases the risk of acute pancreatitis, accounting for a minor but clinically relevant proportion of cases. ${ }^{29-32}$ Although a few patients can develop pancreatitis when their fasting triglyceride concentration is $5-10 \mathrm{mmol} / \mathrm{L}$, its risk becomes clinically significant when fasting measurements exceed ro mmol/L, a level at which chylomicrons are present. ${ }^{29-32} \mathrm{~A}$ threshold value of $1000 \mathrm{mg} / \mathrm{dL}$ (about II. $3 \mathrm{mmol} / \mathrm{L}$ ) is often cited, but the clinical relevance and implications of a rounded threshold of Io $\mathrm{mmol} / \mathrm{L}$ for "very high" triglycerides are comparable. The capacity of the pancreas to produce an exocrine lipase might explain the specificity of pancreatic involvement.

Some patients with triglyceride-related pancreatitis probably have pre-existing abnormalities in their metabolism of lipoprotein. ${ }^{1}$ Pancreatitis risk is accentuated by any factor that can increase plasma triglycerides past $10 \mathrm{mmol} / \mathrm{L}$. Triglyceride-induced pancreatitis can be preceded by episodic nausea and epigastric pain, during which serum amylase may not exceed common diagnostic cutoffs. Associated clinical clues include eruptive xanthomata or lipemia retinalis (Fig. I).

The onset of full-blown acute pancreatitis can be prevented by restriction of dietary fat or the use of fibrates. Treatment of acute cases includes hemodynamic stabilization, cessation of all oral intake, placement of a nasogastric tube and control of metabolic disturbances. Restricted energy intake is associated with a brisk decrease in plasma triglyceride levels. Plasmapheresis has been attempted in extreme cases, but the benefit was transient. The threshold for developing pancreatitis can vary widely; some asymptomatic people live with triglyceride levels chronically in excess of $40 \mathrm{mmol} / \mathrm{L}$.

\section{Nonpharmacologic treatment}

People with hypertriglyceridemia are frequently obese, insulin-resistant, hypertensive or diabetic, all of which are risk factors for cardiovascular disease. Treatment includes weight reduction, dietary modification and exercise. Dietary modification should decrease weight, overall energy intake, and intakes of fat and refined carbohydrates (i.e., foods with a high glycemic index). ${ }^{33}$ Alcohol consumption should be reduced or eliminated. In cases of severe hyperchylomicronemia, recommended fat intake is restricted to $10 \%-15 \%$ of total energy intake (about $15-20 \mathrm{~g} / \mathrm{d}$ ), with reductions in saturated, unsaturated and trans fats. ${ }^{3}$ Consultation with a dietician can be very helpful. For less severe cases of hypertriglyceridemia, restrictions to saturated and trans fat intake and increased aerobic activity can reduce plasma levels of triglycerides. The National Cholesterol Education Program advises a carbohydrate intake of $55 \%-60 \%$ and a protein intake of $15 \%-20 \%$ of daily dietary intake, whereas total and saturated fat should not surpass $30 \%$ and $7 \%$, respectively. ${ }^{3}$ Plasma triglyceride response to diet and weight loss is about $25 \%,{ }^{34}$ with marked variation among patients. ${ }^{34}$

Omega-3 fatty acids (e.g., eicosapentaenoic and docosahexaenoic acid) are components of both the Mediterranean diet and of fish oils. ${ }^{35}$ Daily consumption of $4 \mathrm{~g}$ of omega-3 fatty acids, along with with restricted energy and saturated-fat intakes, can reduce plasma triglyceride levels by as much as $20 \%$. However, omega-3 fatty acids are rarely effective when used as the sole triglyceride-lowering therapy.

\section{Pharmacologic therapy to lower the risk of cardiovascular disease}

In general, monotherapy with a pharmacologic agent should be attempted first, together with dietary adjustments. Combination treatment may be required for refractory severe hypertriglyceridemia, but should be attempted only with caution and frequent monitoring of serum concentrations of creatine kinase, transaminase and creatinine.

\section{Fibrates}

Fibric acid derivatives such as gemfibrozil, bezafibrate and fenofibrate are a mainstay of hypertriglyceridemia treatment. ${ }^{36}$ These fibrates can reduce plasma triglyceride levels by up to $50 \%$ and raise plasma HDL-C concentrations as much as $20 \%$ (although these percentages vary). The complex mechanism of action of fibrates includes modulation of the activity of peroxisome proliferator-activated receptor- $\alpha$ in the liver, with reduced hepatic secretion of VLDL and increased lipolysis of plasma triglycerides. ${ }^{37}$ Fibrates reduce the quantity of small, dense LDL particles and increase HDL-C. ${ }^{38}$ Fibrates can sometimes raise plasma LDL-C concentration, which in turn necessitates a change to another drug or the addition of a second agent. Fibrate therapy is generally very well tolerated, with very rare reports of it leading to hepatitis or myositis. ${ }^{36}$

The effectiveness of fibrates in reducing cardiovascular disease outcomes has been of long-standing concern. Earlier studies $^{38-40}$ showed that fibrates reduced cardiovascular event rates; for instance, gemfibrozil resulted in a statistically significant benefit among men with high triglyceride and low HDL-C readings. ${ }^{40}$ The recent Fenofibrate Intervention and Event Lowering in Diabetes (FIELD) study found that plasma triglyceride, LDL and HDL-C levels in diabetic patients re- 
sponded favourably to treatment with fenofibrate, but the reduction in the prespecified end point of cardiovascular disease (I6\%) was nonsignificant. ${ }^{41}$ Secondary and tertiary outcomes (e.g., nonfatal myocardial infarction, coronary revascularization, and progression of albuminuria and retinopathy) were significantly reduced. Serum creatinine was about $15 \%$ higher in the group taking fenofibrate and fell when fenofibrate was discontinued, which suggests a functional rather than a structural change. ${ }^{41}$ However, subgroup analyses showed significant benefits of fenofibrate in patients without prior cardiovascular disease and after adjustment for "drop-in" statin use in the placebo group (i.e., increased use of prescribed statins by patients not treated with fenofibrate). Thus, enthusiasm for fibrate therapy is lower than that for statins, although selected patients might benefit. ${ }^{42}$

\section{Statins}

Statins are 3-hydroxy-3-methylglutaryl-coenzyme A reductase inhibitors. Newer statins used at higher doses can markedly reduce levels of triglycerides. They are not, however, a firstline therapy when triglyceride levels exceed $5 \mathrm{mmol} / \mathrm{L}$.

An advantage of statins is the preponderance of evidence for reductions in coronary heart disease end points, ${ }^{43}$ especially among patients with type 2 diabetes. ${ }^{44}$ Like fibrates, statins are generally well tolerated and rarely cause myopathy or hepatic toxicity. Safety data from the FIELD study showed no rhabdomyolysis among the more than Iooo patients who took both fenofibrate and a statin. ${ }^{41}$ Potential beneficial effects of the combination of a statin and fibrate in the treatment of type 2 diabetes are currently being investigated in the ongoing Action to Control Cardiovascular Risk in Diabetes (ACCORD) study. ${ }^{45}$

\section{Niacin}

The daily consumption of up to $3 \mathrm{~g}$ of niacin (nicotinic acid) can lower plasma triglyceride levels by up to $45 \%$, raise plasma HDL-C by up to $25 \%$, and reduce plasma LDL-C by up to $20 \%{ }^{46}$ Older clinical trials suggested a reduction in cardiovascular events related to niacin treatment. ${ }^{47}$ However, niacin frequently causes light-headedness, cutaneous flushing, or pruritus. These adverse effects can be minimized by starting therapy at low doses then gradually increasing the daily dose; concomitant use of acetylsalicylic acid; or use of longer-acting preparations, such as Niaspan..$^{48}$ Less common adverse effects include elevations of liver enzymes, increased levels of uric acid, gastrointestinal distress and worsened glucose tolerance.

\section{Other lipid-lowering medications}

Bile acid-binding resins worsen plasma triglyceride concentrations, ${ }^{36}$ whereas cholesterol-absorption inhibitors (e.g., ezetimibe) do not. ${ }^{49} \mathrm{~A}$ combination of fenofibrate and ezetimibe was recently shown to be safe and effective for patients with elevated triglyceride and LDL-C levels..$^{50}$ Canada recently joined the United States in approving this combination for therapeutic use.

\section{Emerging treatments}

Rimonabant is a cannabinoid-1 receptor antagonist that decreases hunger and reduces food intake. ${ }^{51,52}$ Four phase-3 randomized, double-blind, placebo-controlled trials (the Rimonabant in Obesity trials, namely RIO-Europe, -Lipids, -North America and -Diabetes $)^{52-56}$ have each evaluated rimonabant in various patient groups, showing successful, persistent reductions in obesity variables in the treatment groups, with concomitant improvements in metabolic bio-

Table 1: Assessment and action strategies for elevated plasma triglyceride concentrations [TG]

\begin{tabular}{|c|c|c|}
\hline $\begin{array}{c}{[\mathrm{TG}],} \\
\mathrm{mmol} / \mathrm{L}\end{array}$ & Action and comments & $\begin{array}{l}\text { Retest } \\
\text { interval, } \\
\text { mo* }\end{array}$ \\
\hline$<2$ & $\begin{array}{l}\text { Continue current management } \\
\text { - Reassess lipid profile regularly, to ensure } \\
\text { that }[\mathrm{LDL}-\mathrm{C}] \text { is at target }\end{array}$ & $6-12$ \\
\hline \multirow[t]{3}{*}{$\geq 2,<5$} & $\begin{array}{l}\text { 1. Therapeutic lifestyle measures } \\
\text { - Weight control } \\
\text { - Reduce dietary fat, simple sugars } \\
\text { - Reduce alcohol intake } \\
\text { - Increase physical activity } \\
\text { Reassess lipid profile regularly, to ensure that } \\
\text { [LDL-C] is at target }\end{array}$ & 3-6 \\
\hline & $\begin{array}{l}\text { 2. Manage other secondary factors } \\
\text { - Control glycemia, if diabetic } \\
\text { - Reassess medications; consider lipid-neutral } \\
\text { alternatives }\end{array}$ & \\
\hline & $\begin{array}{l}\text { 3. Consider pharmacologic treatment } \\
\text { - Intensify LDL-lowering (e.g., statin therapy) } \\
\text { - Fish oil (omega-3 fatty acid) } \\
\text { - Niacin (e.g., extended release) }\end{array}$ & \\
\hline \multirow[t]{2}{*}{$\geq 5,<10$} & $\begin{array}{l}\text { 4. Intensify steps } 1-3 \text {, above } \\
\text { - }[\mathrm{LDL}-\mathrm{C}] \text { cannot be estimated when } \\
\text { [triglycerides] }>5 \mathrm{mmol} / \mathrm{L} \\
\text { - Apolipoprotein B determination might be } \\
\text { helpful }\end{array}$ & $2-3$ \\
\hline & $\begin{array}{l}\text { 5. Consider fibrate therapy, e.g., } \\
\text { - Bezafibrate (Bezalip) } 400 \mathrm{mg} / \mathrm{d} \\
\text { - Fenofibrate } \\
\text { - Lipidil micro } 200 \mathrm{mg} / \mathrm{d} \\
\text { - Lipidil supra } 160 \mathrm{mg} / \mathrm{d} \\
\text { - Lipidil EZ } 145 \mathrm{mg} / \mathrm{d} \\
\text { - Gemfibrozil (Lopid) } 600-1200 \mathrm{mg} / \mathrm{d}\end{array}$ & \\
\hline \multirow[t]{3}{*}{$\geq 10$} & $\begin{array}{l}\text { 6. Further intensify steps } 1-3 \\
\text { With acute pancreatitis: } \\
\text { - Very-low-fat diet ( } 10 \%-15 \% \text { of energy intake) } \\
\text { - Cessation of alcohol } \\
\text { - Insulin, if indicated for glycemic control } \\
\text { - Admit patient to hospital } \\
\text { - Nothing by mouth: IV fluid replacement } \\
\text { - Plasma exchange is unhelpful }\end{array}$ & 1-2 \\
\hline & $\begin{array}{l}\text { 7. Initiate fibrate therapy } \\
\text { - Monitor serum [creatinine] }\end{array}$ & \\
\hline & 8. Consider specialist referral & \\
\hline
\end{tabular}

Note: [] = concentration, LDL = low-density lipoprotein, LDL-C = low-density lipoprotein-cholesterol, IV = intravenous.

*For re-evaluation of lipid profile. 
markers, including triglycerides. ${ }^{52-56}$ However, adverse effects such as depression and anxiety were also more common in those groups ${ }^{54}$ Nonetheless, rimonabant seems to be a promising new treatment for obesity and dyslipidemia.

Glitazar drugs are dual agonists of peroxisome proliferatoractivated receptor- $\alpha$ (similar to fibrates) and $-\gamma$ (similar to thiazolidinediones) and hold theoretical advantages for treatment of type 2 diabetes and metabolic syndrome. However, an analysis of phase 2 and 3 trials found significant associations between muraglitazar and death, myocardial infarction and stroke. ${ }^{56}$ This agent and others of the class have since been withdrawn from clinical use.

LPL gene therapy. Hyperlipoproteinemia type 1 caused by lipoprotein lipase deficiency causes recurrent and potentially fatal pancreatitis. ${ }^{1}$ The incidence of lipoprotein lipase deficiency can be up to about I:5000 in regions of Eastern Quebec because of a genetic founder effect; $;{ }^{57}$ in such populations, gene therapy is an interesting, if still theoretical, consideration. Management of lipoprotein lipase deficiency with fibrates is modestly effective. As for nonpharmaceutical treatments, most patients find it difficult to adhere to the recommended diet of less than I0\% (of total energy intake from) fat. Even with aggressive management, plasma triglyceride levels in patients with familial chylomicronemia often remained over the $10 \mathrm{mmol} / \mathrm{L}$ threshold. Gene therapy, however, may help treat monogenic lipoprotein lipase deficiency, ${ }^{58}$ since lipoprotein lipase can be targeted to skeletal muscle: a modest increase in activity would then dramatically reduce plasma triglyceride levels. Using a "beneficial" allele of $L P L$, gene therapy has corrected elevated triglyceride levels in animals, ${ }^{59}$ which paves the way for trials involving people.

\section{Target triglyceride goals}

In 2006, guidelines from the Canadian Working Group on Hypercholesterolemia and Other Dyslipidemias no longer recommended a specific triglyceride target, ${ }^{60}$ whereas those from the National Cholesterol Education Program in the United States recommended that if triglyceride concentration exceeds I.7 $\mathrm{mmol} / \mathrm{L}$, therapy should be aimed at attaining the LDL-C target specified for the patient's risk stratum of coronary heart disease. ${ }^{3}$ Table I presents a proposed strategy for management of patients whose triglyceride levels are elevated.

\section{Conclusions}

Moderate hypertriglyceridemia is a risk factor for cardiovascular disease; severe hypertriglyceridemia, for pancreatitis. Although reductions in plasma triglycerides probably reduce the risk of cardiovascular disease, the clinical trial evidence for fibrate monotherapy is weaker than that provided for reductions of plasma LDL-C concentrations. Nonetheless, improvement of triglyceride levels by control of secondary factors will help reduce risk of cardiovascular disease. The use of fibrates as prophylaxis against pancreatitis when plasma triglyceride results exceed Io $\mathrm{mmol} / \mathrm{L}$ is less contentious. In the next few years, new clinical trials (especially of statin-fibrate combination treatment) and the availability of new types of treatment may result in an evolution of the current approach to treating elevated plasma triglycerides.
This article has been peer reviewed.

From the Schulich School of Medicine and Dentistry, University of Western Ontario, London, Ont.

\section{Competing interests: None declared.}

Contributors: Khalid Al-Shali and Robert Hegele drafted the manuscript. George Yuan and Robert Hegele participated in the critical revision of the article. All authors have approved the final version for publication.

Acknowledgements: We were supported by the Jacob J. Wolfe Chair in Functional Genomics, the Edith Schulich Vinet Canada Research Chair (Tier I) in Human Genetics, a Career Investigator award from the Heart and Stroke Foundation of Ontario and operating grants from the Canadian Institutes for Health Research, the Heart and Stroke Foundation of Ontario, the Ontario Research Fund, and Genome Canada through the Ontario Genomics Institute. George Yuan was supported by the University of Western Ontario Summer Research Training Program and by the Heart and Stroke Foundation of Ontario's Irwin Bernick Scholarship.

\section{REFERENCES}

I. Hegele RA. Monogenic dyslipidemias: window on determinants of plasma lipoprotein metabolism. Am J Hum Genet 2001;69:116r-77.

2. Hodis HN, Mack WJ, Krauss RM, et al. Pathophysiology of triglyceride-rich lipoproteins in atherothrombosis: clinical aspects. Clin Cardiol I999;22:III5-20.

3. Expert Panel on Detection, Evaluation, and Treatment of High Blood Cholesterol in Adults. Executive summary of the third report of the National Cholesterol Education Program (NCEP) Expert Panel on Detection, Evaluation, and Treatment of High Blood Cholesterol in Adults (Adult Treatment Panel III). JAMA 2001;285: 2486-97.

4. Goldstein JL, Schrott HG, Hazzard WR, et al. Hyperlipidemia in coronary heart disease. II. Genetic analysis of lipid levels in 176 families and delineation of a new inherited disorder, combined hyperlipidemia. JClin Invest 1973;52:1544-68.

5. Lee JC, Lusis AJ, Pajukanta P. Familial combined hyperlipidemia: upstream transcription factor I and beyond. Curr Opin Lipidol 2006;17:I0I-9.

6. Pollex RL, Hegele RA. Complex trait locus linkage mapping in atherosclerosis: time to take a step back before moving forward? Arterioscler Thromb Vasc Biol 2005;25:I54I-4.

7. Walden CC, Hegele RA. Apolipoprotein E in hyperlipidemia. Ann Intern Med I994;120:1026-36.

8. Lemieux I, Pascot A, Couillard C, et al. Hypertriglyceridemic waist: a marker of the atherogenic metabolic triad (hyperinsulinemia; hyperapolipoprotein B; small, dense LDL) in men? Circulation 2000;102:179-84.

9. Pollex RL, Hegele RA. Genetic determinants of the metabolic syndrome. Nat Clin Pract Cardiovasc Med 2006;3:482-9.

Io. Kaysen GA, de Sain-van der Velden MG. New insights into lipid metabolism in the nephrotic syndrome. Kidney Int Suppl 1999;71:S18-2I.

II. Warth MR, Arky RA, Knopp RH. Lipid metabolism in pregnancy. II. Altered lipid composition in intermediate, very low, low and high-density lipoprotein fractions. J Clin Endocrinol Metab 1975;41:649-55.

I2. Hsia SH, Connelly PW, Hegele RA. Successful outcome in severe pregnancy-associated hyperlipemia: a case report and literature review. Am JMed Sci 1995;309:213-8.

13. Clark JM. The epidemiology of nonalcoholic fatty liver disease in adults. J Clin Gastroenterol 2006;40:S5-10.

14. Farrell GC, Larter CZ. Nonalcoholic fatty liver disease: from steatosis to cirrhosis. Hepatology 2006;43:S99-II2.

15. Athyros VG, Mikhailidis DP, Didangelos TP, et al. Effect of multifactorial treatment on non-alcoholic fatty liver disease in metabolic syndrome: a randomised study. Curr Med Res Opin 2006;22:873-83.

I6. Calza L, Manfredi R, Chiodo F. Dyslipidaemia associated with antiretroviral therapy in HIV-infected patients. J Antimicrob Chemother 2004;53:10-4.

17. Friis-Moller N, Sabin CA, Weber R, et al. Data Collection on Adverse Events of Anti-HIV Drugs (DAD) Study Group. Combination antiretroviral therapy and the risk of myocardial infarction. N Engl J Med 2003;349:1993-2003.

18. Green ML. Evaluation and management of dyslipidemia in patients with HIV infection. J Gen Intern Med 2002;17:797-810.

19. Calza L, Manfredi R, Colangeli V, et al. Substitution of nevirapine or efavirenz for protease inhibitor versus lipid-lowering therapy for the management of dyslipidaemia. AIDS 2005;I9:I05I-8.

20. American Diabetes Association; American Psychiatric Association; American Association of Clinical Endocrinologists; North American Association for the Study of Obesity. Consensus development conference on antipsychotic drugs and obesity and diabetes. Diabetes Care 2004;27:596-601.

2I. Tarricone I, Casoria M, Gozzi BF, et al. Metabolic risk factor profile associated with use of second generation antipsychotics: a cross sectional study in a community mental health centre. BMC Psychiatry 2006;6:II.

22. Bushe $\mathrm{C}$, Holt $\mathrm{R}$. Prevalence of diabetes and impaired glucose tolerance in patients with schizophrenia. BrJPsychiatry Suppl 2004;47:S67-71. 
23. Assmann G, Cullen P, Schulte H. The Munster Heart Study (PROCAM). Results of follow-up at 8 years. Eur Heart Jig98;Ig(Suppl A):A2-II

24. Criqui $\mathrm{MH}$, Heiss $\mathrm{G}$, Cohn $\mathrm{R}$, et al. Plasma triglyceride level and mortality from coronary heart disease. N Engl J Med I993;328:1220-5.

25. Hokanson JE, Austin MA. Plasma triglyceride level is a risk factor for cardiovascular disease independent of high-density lipoprotein cholesterol level: a metaanalysis of population-based prospective studies. J Cardiovasc Risk 1996;3:213-9.

26. Benlian P, de Gennes J-L, Foubert L, et al. Premature atherosclerosis in patients with familial chylomicronemia caused by mutations in the lipoprotein lipase gene. NEngl J Med I996;335:848-54.

27. Zilversmit DB. Atherogenesis: a postprandial phenomenon. Circulation I979;60: $473-85$.

28. Tushuizen ME, Diamant M, Heine RJ. Postprandial dysmetabolism and cardiovascular disease in type 2 diabetes. Postgrad Med J 2005;8I:I-6.

29. Santamarina-Fojo S. The familial chylomicronemia syndrome. Endocrinol Metab Clin North Am I998;27:55I-67.

30. Toskes PP. Hyperlipidemic pancreatitis. Gastroenterol Clin North Am I990;19: 783-9I.

3I. Athyros VG, Giouleme OI, Nikolaidis NL, et al. Long-term follow-up of patients with acute hypertriglyceridemia-induced pancreatitis. J Clin Gastroenterol 2002; 34:472-5.

32. Yadav D, Pitchumoni CS. Issues in hyperlipidemic pancreatitis. J Clin Gastroenter ol 2003;36:54-62.

33. Jenkins DJ, Kendall CW, Augustin LS, et al. Glycemic index: overview of implications in health and disease. Am J Clin Nutr 2002;76:266S-73S.

34. Gerhard GT, Ahmann A, Meeuws K, et al. Effects of a low-fat diet compared with those of a high-monounsaturated fat diet on body weight, plasma lipids and lipoproteins, and glycemic control in type 2 diabetes. Am J Clin Nutr 2004;80:668-73.

35. Hooper L, Thompson RL, Harrison RA, et al. Risks and benefits of omega 3 fats for mortality, cardiovascular disease, and cancer: systematic review. BMJ 2006; 332:752-60.

36. Barter PJ, Rye KA. Cardioprotective properties of fibrates: which fibrate, which patients, what mechanism? Circulation 2006;113:1553-5.

37. Rubins HB, Robins SJ, Collins D, et al. Diabetes, plasma insulin, and cardiovascular disease: subgroup analysis from the Department of Veterans Affairs high-density lipoprotein intervention trial (VA-HIT). Arch Intern Med 2002;162:2597-604.

38. Frick MH, Elo O, Haapa K, et al. Helsinki Heart Study: primary-prevention tria with gemfibrozil in middle-aged men with dyslipidemia. Safety of treatment, changes in risk factors, and incidence of coronary heart disease. $N$ Engl J Med 1987;317:1237-45

39. Tenenbaum A, Motro M, Fisman EZ, et al. Bezafibrate for the secondary prevention of myocardial infarction in patients with metabolic syndrome. Arch Intern Med 2005; I65:II54-6o.

40. Rubins HB, Robins SJ, Collins D, et al; Veterans Affairs High-Density Lipoprotein Cholesterol Intervention Trial Study Group. Gemfibrozil for the secondary prevention of coronary heart disease in men with low levels of high-density lipoprotein cholesterol. NEngI JMed I999;34I:4I0-8.

4I. Keech A, Simes RJ, Barter P, et al; FIELD study investigators. Effects of long-term fenofibrate therapy on cardiovascular events in 9795 people with type 2 diabetes mellitus (the FIELD study): randomised controlled trial [published errata in Lancet 2006;368:I4I5 and I420]. Lancet 2005;366:I849-6I.

42. Barter P. Managing diabetic dyslipidaemia - beyond LDL-C:HDL-C and triglycerides. Atheroscler Suppl 2006;7:17-2I
43. Topol EJ. Intensive statin therapy - a sea change in cardiovascular prevention. $N$ Engl J Med 2004;350:1562-4.

44. Gami AS, Montori VM, Erwin PJ, et al; Evidence in Diabetes Enquiry System (EVIDENS) Research Group. Systematic review of lipid lowering for primary prevention of coronary heart disease in diabetes. $B M J$ 2003;326:528-9.

45. Action to Control Cardiovascular Risk in Diabetes. Study Protocol 2005. Available: www.accordtrial.org/public/index.cfm (accessed 2006 Oct I9).

46. Carlson LA. Nicotinic acid: the broad-spectrum lipid drug. A 5oth anniversary review. Intern Med 2005;258:94-II4.

47. Canner PL, Berge KG, Wenger NK, et al. Fifteen year mortality in Coronary Drug Project patients: long-term benefit with niacin. J Am Coll Cardiol I986;8:1245-55.

48. Carlson LA. Niaspan, the prolonged release preparation of nicotinic acid (niacin), the broad-spectrum lipid drug. Int J Clin Pract 2004;58:706-13.

49. Darkes MJ, Poole RM, Goa KL. Ezetimibe. Am J Cardiovasc Drugs 2003;3:67-76.

50. McKenney JM, Farnier M, Lo KW, et al. Safety and efficacy of long-term co-administration of fenofibrate and ezetimibe in patients with mixed hyperlipidemia. J Am Coll Cardiol 2006;47:1584-7.

51. Boyd ST, Fremming BA. Rimonabant - a selective CB1 antagonist. Ann Pharmacother 2005;39:684-90.

52. Gelfand EV, Cannon CP. Rimonabant: a cannabinoid receptor type I blocker for management of multiple cardiometabolic risk factors. J Am Coll Cardiol 2006;47: I9I9-26.

53. Van Gaal LF, Rissanen AM, Scheen AJ, et al; RIO-Europe Study Group. Effects of the cannabinoid-1 receptor blocker rimonabant on weight reduction and cardiovascular risk factors in overweight patients: 1-year experience from the RIO-Europe study. Lancet 2005;365:1389-97.

54. Despres JP, Golay A, Sjostrom L; Rimonabant in Obesity-Lipids Study Group. Effects of rimonabant on metabolic risk factors in overweight patients with dyslipidemia. NEngl JMed 2005;353:212I-34.

55. Pi-Sunyer FX, Aronne LJ, Heshmati HM, et al; RIO-North America Study Group. Effect of rimonabant, a cannabinoid-1 receptor blocker, on weight and cardiometabolic risk factors in overweight or obese patients, RIO-North America: a randomized controlled trial. JAMA 2006;295:76I-75

56. Nissen SE, Wolski K, Topol EJ. Effect of muraglitazar on death and major adverse cardiovascular events in patients with type 2 diabetes mellitus. JAMA 2005;294: $258 \mathrm{I}-6$.

57. Gagné C, Brun LD, Julien P, et al. Primary lipoprotein-lipase-activity deficiency: clinical investigation of a French Canadian population. CMAJ I989;I40(4):405-II.

58. Rip J, Nierman MC, Sierts JA, et al. Gene therapy for lipoprotein lipase deficiency: working toward clinical application. Hum Gene Ther 2005;16:1276-86.

59. Ross CJ, Liu G, Kuivenhoven JA, et al. Complete rescue of lipoprotein lipase-deficient mice by somatic gene transfer of the naturally occurring $L P L S 447 X$ beneficial mutation. Arterioscler Thromb Vasc Biol 2005;25:2143-50.

6o. McPherson R, Frohlich J, Fodor G, et al. Canadian Cardiovascular Society position statement - recommendations for the diagnosis and treatment of dyslipidemia and prevention of cardiovascular disease. Can J Cardiol 2006;22:913-27.

Correspondence to: Dr. Robert Hegele, Blackburn Cardiovascular Genetics Laboratory, Robarts Research Institute, 406 - Ioo Perth Dr., London ON N6A 5K8; fax 519 663-3037; hegele@robarts.ca

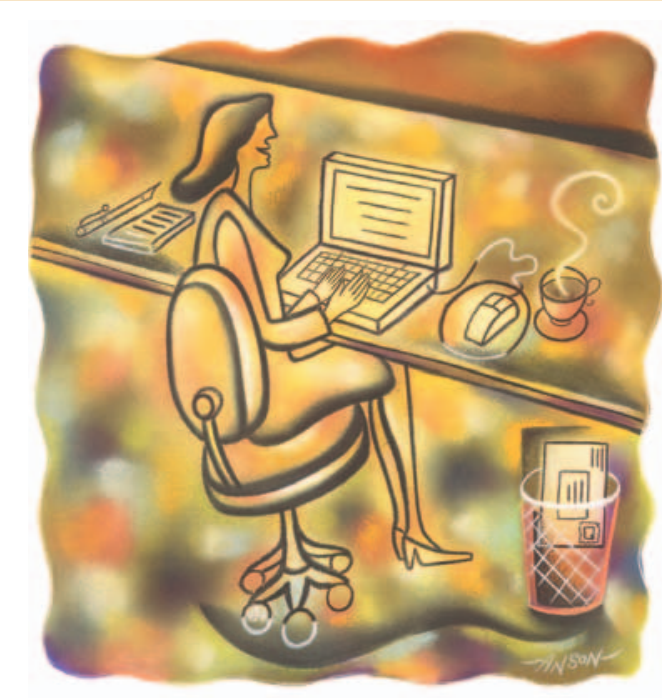

Online manuscript submissions and peer review

NOW AVAILABLE AT CMAJ http://mc.manuscriptcentral.com/cmaj 